DOI: 10.12731/2077-1770-2018-4-224-235

УДК 811.133.1

\title{
ПРОБЛЕМА ГЕНДЕРА ВО ФРАНЦУЗСКОМ ЯЗЫКЕ: ЛЕКСИЧЕСКИЙ И ГРАММАТИЧЕСКИЙ УРОВНИ
}

\section{Черкесова 3.В.}

Цель. Статья посвящена исследованию гендерных признаков единиц лексического и грамматического уровней франиузского языка, изучению особенностей содержания и композиции концепта «женщина» в разных возрастных и гендерных группах носителей исследуемого языка. Во франиузском языке существует два рода-мужской и женский, при этом доминирующим является мужской род.

Методы проведения работы - экспериментальный и описательный методы.

Результаты. Анализ реализации лексических и грамматических единиц как гендерных маркеров, используемых языковой личностью во французском языковом сознании, показал, что категория рода во франиузском языке - явление детерминирующее, динамичное, способствующее возникновению гендерных асимметрий в языке.

Область применения результатов. Полученнье результаты могут быть использованы в проведении лингвоконцептуальных анализов по материалам других языков.

Ключевые слова: гендер; франиузский язык; феминность; маскулинность; речевые маркеры.

\section{THE PROBLEM OF THE GENDER IN THE FRENCH LANGUAGE: LEXICAL AND GRAMMAR LEVELS}

\section{Cherkesova Z.V.}

Purpose. It is the gender-related features of the lexical and grammatical levels of the French language that are investigated. In French, 
there are two genders, i.e., male and female, the masculine gender being a dominant one.

Methodology. Experimental and descriptive methods.

Results. Analysis of the implementation of lexical and grammatical units as gender markers used by the linguistic persona in French linguistic consciousness demonstrated that the category of the gender in French is a determinative, dynamic phenomenon that contributes to the emergence of gender asymmetries in the language.

Practical implications. The received results can be used in carrying out the linguistic-conceptual analyses on materials of other languages.

Keywords: gender; French language; femininity; masculinity; speech markers.

Процесс антропологизации знаний, который в современной гуманитарной науке охватил практически все сферы научного познания, вышел за рамки структурного подхода к изучаемым явлениям и стремится осмыслить их через призму человека. В этом отношении одним из факторов формирования социокультурной ситуации в обществе является гендер, который определяет одни черты как женские, другие как мужские. Гендерные нормы поведения, заложенные в ментальной картине мира, находят отражение в языке народа.

Лингвистическая модель функционирования языка и речи в современном обществе включает структуру взаимообусловленных и взаимозависимых составляющих, связанных, с одной стороны, с физиологическими и психологическими особенностями индивида и спецификой формирования индивидуального речевого кода под влиянием социальных (культурологических, этноментальных и др.) и экономических (принадлежность к определенной группе, классу, сфере и т.д.) факторов - с другой. Такая интегрированная модель предполагает учет как экстралингвистических, так и лингвистических аспектов речевой деятельности индивида с ориентацией в последнем случае на особенности фонетического, лексического, синтаксического планирования и реализации речевого высказывания 
индивидом в акте коммуникации, т.е. на специфику формирования индивидуального языкового варианта (идиолекта) [3, с. 13].

Как отмечает В.М. Алпатов, оппозиция мужских и женских вариантов представляет собой, по всей вероятности, древнейший тип дифференциации языка. Можно предположить, что она существовала уже на ранних этапах развития человечества, будучи связанной с разделением труда между полами. В этой связи мужчины и женщины оперируют разными словами, связанными с их профессиональной специализацией [1, с. 58]

Исследование гендерных признаков единиц лексического и грамматического уровней представляется важным и актуальным на сегодняшний день.

Как известно, грамматическая категория рода свойственна разным частям речи и заключается в распределении слов по двум или трем классам (мужской, женский и средний), традиционно соотносимым с признаками пола или их отсутствием. Применительно к функционированию гендерного признака в современном французском языке на уровне лексики и грамматики ученые-лингвисты уделяют внимание фиксации и анализу важных речевых и языковых изменений, связанных с изменением представления о ролевых функциях мужчин и женщин в современном французском обществе.

Во французском языке, в отличие от русского, существует только два рода - мужской и женский. При этом доминирующим является категория маскулинности, т.е. мужской род. Как утверждает О.И. Богомолова, «в современном французском языке грамматический род - категория чисто формальная, не опирающаяся на смысловые противоположения, но, тем не менее, вполне устойчивая» $[2$, c. 62].

На современном этапе развития французского языка категория рода продолжает изменяться. Наиболее ярким проявлением этого процесса является феминизация существительных, которая в последнее столетие получила широкое распространение и привела к тому, что существительные мужского рода образуют женский род при помощи различных способов. Например, существительное иn 
lecteur (лектор, читатель), изначально являющийся существительным мужского рода, может менять свой род на женский - иne lectrice (лекторша, читательница). Данное существительное может также употребляться дифференцированно: в форме мужского рода единственного числа - un lecteur и в форме женского рода множественного числа - des lectrices.

Мужской род во французском языке является универсальным и выполняет функцию так называемого «общего» рода. В некоторых случаях он служит для обозначения лиц любого пола или группы лиц разного пола. Так, если имеются в виду преподаватели одного учебного учреждения, включая и мужчин, и женщин, употребляется форма les maîtres (maître - м.p., maîtresse - ж.p.).

Часто имена существительные женского рода являются производными от существительных мужского рода: un traducteur - une traductrice, un mâle - une female, un maître - une maîtresse и т.п. При этом при переходе из мужского в женский род некоторые имена существительные приобретают негативную окраску: un courtisan (придворный) - une courtisane (куртизанка) и т.п.

Во французском языке есть слово hoтmе, которое включает понятия «мужчина» и «женщина». Однако понятие «женщина» лишь формально включено в данную дефиницию. Общечеловеческое понятие l'homme больше является категорией маскулинной, чем фемининной, поэтому во французском языке наблюдается отождествление понятий «человек» и «мужчина», интегрированных в понятии l'hoтmе.

Во французском языке имеется множество существительных, род которых не имеет четкого обозначения. Для некоторых же существительных в настоящее время категория рода вообще не установлена.

В современном французском обществе женщины уже не считаются «слабым полом». Об этом свидетельствует тот факт, что многие женщины адаптируются к профессиям, которые раньше считались «мужскими». На сегодняшний день профессии docteur (врач), peintre (художник), е́crivain (писатель), professeur (преподаватель, 
профессор), juge (судья), financier финансист), avocat (адвокат), ingénieur (инженер) в равной мере относятся как к мужчинам, так и к женщинам, но эти существительные не имеют женского рода. В некоторых случаях при определении лиц женского пола вместе с наименованием профессии употребляется лексема femme (женщъина): femme-docteur (женщина-врач), femme-peintre (женщина-художник или художница), femme-écrivain (женщина-писатель или писательница), femme-professeur (женщина-преподаватель), femmejuge (женщина-судья), femme-avocat (женщина-адвокат), femmeingénieur (женщина-инженер) и т.д.

Таким образом, во французском языке не наблюдается четкого обозначения категории рода - разграничения слов по родам. Отсюда вытекает проблема гендера: многочисленные исследования ученых-лингвистов подтверждают факт доминирования маскулинности над феминностью, что способствует образованию гендерных асимметрий во французском языке.

Как и в большинстве других языков, во французском языке женская речь наиболее эмоциональна, женщины чаще употребляют аффектированную и эмоционально окрашенную лексику: различные художественно-изобразительные средства языка, междометия, частицы и т.д. По результатам наблюдения за речью лиц мужского и женского пола разных возрастных категорий (от 18 до 65 лет) и сфер деятельности можно констатировать факт употребления женщинами больше слов, описывающих чувства, эмоции, психофизиологические состояния. Однако во французской речи мы не обнаружили устойчивых, гендерно закрепленных способов и средств выражения эмоций. При этом наблюдаются различия в использовании мужчинами и женщинами тех или иных эмотивных маркеров. Это связано с тем, что мир эмоций и переживаний стоит на первом месте для женщины, а мужчины в любой языковой картине склонны думать, что могут управлять своими эмоциями, сдерживать их.

Как уже отмечено, гендерное различие речевого поведения мужчин и женщин во французском языке обнаруживается в использовании различных эмотивных маркеров. В женской речи наблюдается 
частое использование различных экскламаторов с целью усиления какой-либо эмоции, детализирования и акцентирования смысла высказывания, а также для выражения отношения говорящего к объекту или предмету речи. Для усиления эмоционального воздействия на собеседника француженки употребляют в своей речи модальные наречия-интенсификаторы si, encore, bien, pour que и др., например, для выражения чувства сожаления: Si seulement j'avais pris mon appareil photo! - Если бы только я взяла свой фотоапnарат!; для выражения желания: J'aime bien que tu sois avec moi - Я хочy [xоmела бы очень], чтобы ты был со мной и т.д.

В женской речи также наблюдается частое использование демонстративов-интенсификаторов en, ce qui, c'est, cela и др. Например, для выражения чувства радости: Cela me fait plaisir - Эmо делает меня счастливой (Я рада)!; C'est une belle journée - Это прекрасный день!; для усиления эмоциональности и убедительности высказывания - J'y ferai tout ce que je puis et n'oublierai aucune chose - Я сделаю все, чтобы не забыть ничего (т.е. «постараюсь ничего не забыль»»).

Как в профессиональной, так и обиходно-бытовой речи француженок встречается частое использование вводных слов и слов-указателей и выражений, ориентированных на эмоцию: avec plaisir (с удовольствием), malheureusement (к сожалению), heureusement (к счастью) и т.д., например,:

J'ai accepté l'offre avec plaisir - Я согласилась на предложсение с удовольствием;

- Alors, Jane! Comment ça va, aujourd'hui ?

- Merci, ça va bien, je suis en forme aujourd'hui, Anne.

- Est-ce que vous êtes fatigué aujourd'hui ?

- Heureusement non, je ne suis pas fatigué aujourd'hui.

- Так, Джейн! Как вы сегодня?

- Спасибо, прекрасно, теперь я здорова, Анна.

- Вы устали сегодня?

- К счастью, нет, я сегодня не устала [5]. 
Наблюдения за устной мужской речью указанных выше возрастных категорий (от 18 до 65 лет) и сфер деятельности показали наиболее частое употребление мужчинами инвективов типа zut, diable, parbleu, peste u dp.: Zut! j'ai raté mon autobus - Yepm, я опоздал на свой автобус; Vas Au Diable! - Иди к дьяволу!; Parbleu! tu as tout à fait raison. - Боже [Боже мой, Бог мой]! Tы совершенно прав; Peste! Comment les choses embarrassantes ont travaillé sur! - Чума! Как же неловко все получилось! В речи франиузских мужчин также зафиксировано частое употребление allons для выражения разных эмоций. Например, с утвердительным и побудительным значением: Bon!, c'est bon!, allons! - Hy, это хорошо! Вперед!; со значением удивления: Allons donc! - Нy и ну! и т.д. [5].

Французский язык богат словами-обращениями, различными лексическими оборотами и выражениями, характеризующими гендерные стереотипы мужчин и женщин. Например, для выражения почтения и уважительного отношения к женщине используют обращения: Madame (мн.ч. Mesdames) - Madaм, употребляется по отношению к замужней, разведенной и вдовствующей женщине в значении «Моя госпожа», Mademoiselle (мн.ч. Mesdemoiselles) Мадемуазель, употребляется по отношению к незамужней женщине, девушке в значении «Моя девица». Во французском языке есть также слова и выражения, употребляющиеся для положительной или нейтральной характеристики женщины: ma femme - благоверная, une nana - девушка, une belle poupée - куколка (в значении «красивая»), une femme agreable - приятная женщина, une femme élégante - изысканная (элегантная) женщина, une femme gracieuse грациозная женщина и т.д. [4].

Отрицательный стереотип женщины, пренебрежительное отношение к ней выражается с помощью слов: la chipie - сварливая женщина, мегера, карга, баба, le gendarme - мужеподобная женщина, бой-баба, la belle-de-nuit - ночная бабочка, женщина легкого поведения, la bavarde - болтунья, сорока, la chienne стерва и др. 
Признаком хорошего тона и уважения являются обращения к мужчине: Monsieur (мн.ч. Messieurs) - Mecbe, Mbce, употребляется в значении «Мой господин». Для положительной или нейтральной характеристики мужчины используются слова: l'homme-мужчина, человек, l'oncle - дядя, l'ami - парень, le mari -муж, l'épouse - супруг, le beau - красавец и др.

Во французском языке отрицательный стереотип мужчины (иногда и женщины) создается путем сравнения его с животными или некоторыми растениями:

le coq - петух,

le pingouin - пингвин,

le lapin - кролик,

le cornichon - корнишон.

Кроме подобных сравнений, для отрицательной характеристики мужчины используются слова:

le coureur de jupons - бабник,

le dominé par sa femme - подкаблучник,

le chauffe-la-couche - тюфяк,

la chiffe - мягкотелый, слабохарактерный,

la femmelette - слабак и др.

По результатам проведенного анализа можно констатировать факт, что во французском языке женщинам наиболее свойственно чрезмерно вежливое обращение, а в речи мужчин встречается больше оценочной лексики по отношению к женщинам. При этом в мужской речи наблюдается доминирование лексики, характеризующей внешность женщины. Оценочная лексика француженок, характеризующая мужчин, в основном касается его внутренних данных - характера, уровня интеллекта, хотя и не исключается оценка его физических данных.

Несмотря на асимметрии в использовании тех или иных слов и выражений в речи мужчин и женщин, в современном французском языке нет абсолютно мужских или абсолютно женских речевых маркеров. Некоторые речевые маркеры мужчин и женщин отличаются лишь по частотности употребления.

Результаты анализа нашли отражение в таблицах 1 и 2. 
Таблиия 1.

Выражения гендерных признаков коммуникации во французском языковом сознании: лексический и грамматический уровни

\begin{tabular}{|c|c|c|}
\hline \multirow{2}{*}{ Категория рода } & \multicolumn{2}{|c|}{ Актуализация эмотивныхх маркеров } \\
\hline & мужчины & женшчины \\
\hline $\begin{array}{l}\text { - доминирование мужского рода } \\
\text { (маскулинности); } \\
\text { - феминизация } \\
\text { существительных: } \\
\text { воспроизводство имен } \\
\text { существительных женского рода } \\
\text { от существительных мужского } \\
\text { рода: атоит - une aтоur nouvelle. } \\
\text { При переходе из мужского в } \\
\text { женский род некоторые имена } \\
\text { существительные получают } \\
\text { негативную окраску: соиrtisan } \\
\text { (придворный) - соитtisane } \\
\text { (куртизанка) } \\
\text { - универсальность мужского } \\
\text { рода, выполняющего функцию } \\
\text { так называемого «общего» рода; } \\
\text { - феминизация названий } \\
\text { «мужских» профессий путем } \\
\text { добавления feтmе-: femmе-juge } \\
\text { (женщина-судья), femme-avocat } \\
\text { (женщина-адвокат) и др. }\end{array}$ & $\begin{array}{l}\text { - наиболее } \\
\text { частое } \\
\text { использование } \\
\text { в речи } \\
\text { инвективной } \\
\text { лексики типа } \\
\text { zut, diable, } \\
\text { parbleu, peste } \\
\text { u дp.; } \\
\text { - употребление } \\
\text { междометия } \\
\text { allons для } \\
\text { выражения } \\
\text { разных } \\
\text { эмоций } \\
\text { (например, } \\
\text { удивления: } \\
\text { Allons donc! - } \\
\text { Hy и нy!) }\end{array}$ & 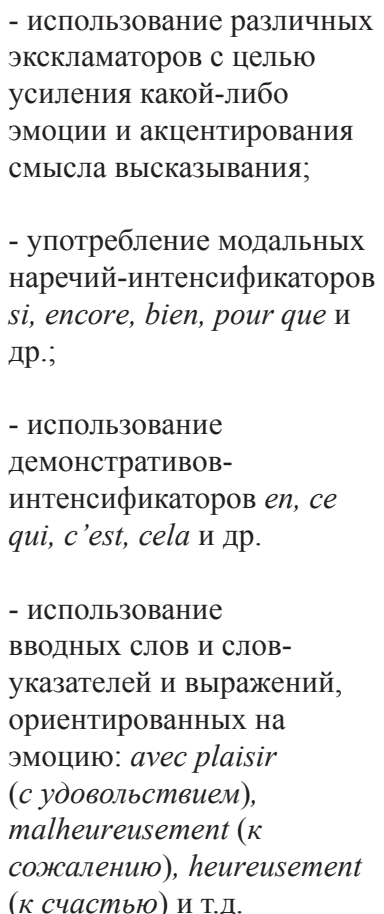 \\
\hline
\end{tabular}

Таблица 2.

Реализация гендерных признаков эмотивно-оценочной лексики во французском языке

\begin{tabular}{|c|c|c|c|c|c|c|c|}
\hline \multicolumn{4}{|c|}{ Мужские оценки (323) } & \multicolumn{4}{|c|}{ Женские оценки (256) } \\
\hline \multicolumn{2}{|c|}{ Мужчина (107) } & \multicolumn{2}{|c|}{ Женщина (216) } & \multicolumn{2}{|c|}{ Мужчина (137) } & \multicolumn{2}{|c|}{ Женщина (119) } \\
\hline $\begin{array}{c}\ll+» \\
31\end{array}$ & $\begin{array}{l}\langle-\gg \\
(76)\end{array}$ & $\begin{array}{c}\langle+» \\
(142)\end{array}$ & $\begin{array}{l}\ll-» \\
(74)\end{array}$ & $\begin{array}{l}\langle+\rangle \\
(84)\end{array}$ & $\begin{array}{l}\langle-\rangle \\
(53)\end{array}$ & $\begin{array}{l}\langle+\rangle \\
(34)\end{array}$ & $\begin{array}{l}\langle-» \\
(85)\end{array}$ \\
\hline $\begin{array}{l}\text { bon (хоро- } \\
\text { ший) - } 23\end{array}$ & \begin{tabular}{|l} 
insensé \\
(безумец, \\
дурак) \\
-33
\end{tabular} & $\begin{array}{l}\text { belle } \\
\text { (красави- } \\
\text { ца, красот- } \\
\text { ка) - } 63\end{array}$ & $\begin{array}{l}\text { bête } \\
\text { (дура, глу- } \\
\text { пая) - } 47\end{array}$ & $\begin{array}{l}\text { beau (кра- } \\
\text { си } \\
\text { вый) - } 54\end{array}$ & $\begin{array}{l}\text { chiffe (мяг- } \\
\text { котелый, } \\
\text { слабоха- } \\
\text { рактер- } \\
\text { ный) - } 39\end{array}$ & $\begin{array}{l}\text { femme soi- } \\
\text { gnée } \\
\text { (ухожен- } \\
\text { ная жен- } \\
\text { щина) - } 15\end{array}$ & $\begin{array}{l}\text { folle } \\
\text { (сумасшед- } \\
\text { шая) - } 18\end{array}$ \\
\hline
\end{tabular}


2018, Volume 10, Number $4 \cdot$ http://soc-journal.ru

Окончание табл. 2.

\begin{tabular}{|c|c|c|c|c|c|c|c|}
\hline $\begin{array}{l}\text { vigoureux } \\
\text { (сильный, } \\
\text { крепкий) } \\
-10\end{array}$ & $\begin{array}{l}\text { stupide } \\
\text { (глупый) } \\
-24\end{array}$ & $\begin{array}{l}\text { charmante } \\
\text { (очарова- } \\
\text { тельная) } \\
-42\end{array}$ & $\begin{array}{l}\text { salope } \\
(\text { неряха) } \\
-21\end{array}$ & $\begin{array}{l}\text { d'esprit } \\
(\text { умный) } \\
-32\end{array}$ & $\begin{array}{l}\text { coureur de } \\
\text { jupons } \\
(\text { бабник) } \\
-27\end{array}$ & $\begin{array}{l}\text { instruite } \\
\text { (образо- } \\
\text { ванная, } \\
\text { умная) - } 9\end{array}$ & $\begin{array}{l}\text { stupide } \\
\text { (глупая, } \\
\text { тупая) - } 13\end{array}$ \\
\hline $\begin{array}{l}\text { beau (от- } \\
\text { личный, } \\
\text { прекрас- } \\
\text { ный) - } 15\end{array}$ & $\begin{array}{l}\text { traître } \\
\text { (преда- } \\
\text { тель) } \\
-19\end{array}$ & $\begin{array}{l}\text { ma femme } \\
\text { (благо- } \\
\text { верная) } \\
-17\end{array}$ & $\begin{array}{l}\text { chipie } \\
\text { (сварли- } \\
\text { вая)-18 }\end{array}$ & $\begin{array}{l}\text { bon } \\
\text { (хороший, } \\
\text { верный) } \\
-26\end{array}$ & $\begin{array}{l}\text { traître } \\
\text { (изменник, } \\
\text { предатель) } \\
-18\end{array}$ & $\begin{array}{l}\text { bопnе } \\
\text { (добрая, } \\
\text { великодуш- } \\
\text { ная) - } 8\end{array}$ & $\begin{array}{l}\text { méchante } \\
\text { (злая) - } 11\end{array}$ \\
\hline $\begin{array}{l}\text { honnête } \\
\text { (порядоч- } \\
\text { ный, чест- } \\
\text { ный) - } 13\end{array}$ & $\begin{array}{l}\text { menteur } \\
\text { (лжец) } \\
-15\end{array}$ & $\begin{array}{l}\text { élégante } \\
\text { (изыскан- } \\
\text { ная, эле- } \\
\text { гантная) } \\
-10\end{array}$ & $\begin{array}{l}\text { gendarme } \\
\text { (мужепо- } \\
\text { добная } \\
\text { женщина, } \\
\text { бой-баба) } \\
\text { - } 13\end{array}$ & $\begin{array}{l}\text { géné-reux } \\
\text { (добрый, } \\
\text { щедрый, } \\
\text { благород- } \\
\text { ный) - } 18\end{array}$ & $\begin{array}{l}\text { egö̈ste } \\
(\text { эгоист) } \\
-14\end{array}$ & \begin{tabular}{|l} 
belle \\
(красивая, \\
красави- \\
ца) - 5
\end{tabular} & $\begin{array}{l}\text { négligé } \\
\text { (неакку- } \\
\text { ратная, не- } \\
\text { ряшливая) } \\
-8\end{array}$ \\
\hline $\begin{array}{l}\text { humain } \\
\text { (добро- } \\
\text { душный, } \\
\text { человеч- } \\
\text { ный) - } 11 \\
\end{array}$ & $\begin{array}{l}\text { grossier } \\
\text { (грубый, } \\
\text { невежли- } \\
\text { вый) - } 11\end{array}$ & $\begin{array}{l}\text { gracieuse } \\
\text { (грациоз- } \\
\text { ная, изящ- } \\
\text { ная) - } 8\end{array}$ & \begin{tabular}{|l} 
bavarde \\
(болтунья \\
сорока) \\
-11
\end{tabular} & $\begin{array}{l}\text { hardi } \\
\text { (дерзкий, } \\
\text { смелый, } \\
\text { отважный) } \\
-10 \\
\end{array}$ & $\begin{array}{l}\text { cruel } \\
\text { (жестокий, } \\
\text { бессердеч- } \\
\text { ный) - } 6\end{array}$ & $\begin{array}{l}\text { sincère } \\
\text { (искрен- } \\
\text { няя, чисто- } \\
\text { сердечная) } \\
-3\end{array}$ & $\begin{array}{l}\text { bavarde } \\
\text { (болтунья, } \\
\text { сорока) } \\
-5\end{array}$ \\
\hline $\begin{array}{l}\text { noble (бла- } \\
\text { городный, } \\
\text { щедрый) } \\
-8\end{array}$ & \begin{tabular}{|l|} 
canaille \\
(мерзавец, \\
негодяй) \\
-9
\end{tabular} & $\begin{array}{l}\text { aimable } \\
\text { (любез- } \\
\text { ная) - } 5\end{array}$ & $\begin{array}{l}\text { belle-de- } \\
\text { nuit (ноч- } \\
\text { ная бабоч- } \\
\text { ка женщи- } \\
\text { на легкого } \\
\text { поведе- } \\
\text { ния) - } 9\end{array}$ & $\begin{array}{l}\text { fort } \\
\text { (сильный) } \\
-10\end{array}$ & $\begin{array}{l}\text { lâche } \\
\text { (трус, } \\
\text { подлый) } \\
-4\end{array}$ & $\begin{array}{l}\text { honnête } \\
\text { (порядоч- } \\
\text { ная) - } 2\end{array}$ & $\begin{array}{l}\text { chienne } \\
\text { (стерва) } \\
-3\end{array}$ \\
\hline $\begin{array}{l}\text { aguichant } \\
\text { (привлека- } \\
\text { тельный) } \\
-4\end{array}$ & \begin{tabular}{|l|} 
émoussé \\
(тупой) - 6
\end{tabular} & $\begin{array}{l}\text { poupée } \\
\text { (куколка) } \\
-3\end{array}$ & $\begin{array}{l}\text { chienne } \\
\text { (стерва) } \\
-6\end{array}$ & $\begin{array}{l}\text { charmant } \\
\text { (прелест- } \\
\text { ный, при- } \\
\text { влекатель- } \\
\text { ный) - } 7\end{array}$ & $\begin{array}{l}d u r \\
\text { (черствый, } \\
\text { жадный) } \\
-2\end{array}$ & $\begin{array}{l}\text { gentile } \\
\text { (милая) } \\
-2\end{array}$ & $\begin{array}{l}\text { scandalisée } \\
\text { (сканда- } \\
\text { листка) - } 2\end{array}$ \\
\hline
\end{tabular}

Таким образом, подробно проанализировав реализацию лексических и грамматических единиц как гендерных маркеров, используемых языковой личностью во французском языковом сознании, мы можем заключить, что категория рода во французском языке представляет собой явление детерминирующее, динамичное, что способствует возникновению гендерных асимметрий в языке.

При рассмотрении проблем гендера во французском языковом сознании релевантной явилась эмотивно-оценочная лексика носителей языка. Гендероприоритетными оказались слова и выражения, свойственные мужской и женской речи. В ходе их исследования 
выявлено, что француженки используют в своей речи большее число эмотивных маркеров, что еще раз подтверждает сложившееся в науке мнение о большей эмоциональности женщин. Что касается оценочных характеристик, в речи французских мужчин их обнаружено больше (323), по сравнению с женской речью (256) [5].

\section{Список литературы}

1. Алпатов В.М. История лингвистических учений. Учебное пособие. М.: Языки русской культуры, 1998. 368 с.

2. Богомолова О.И. Современный французский язык: Теоретический курс. М.: Изд-во лит-ры на иностр-х яз., 1948. 427 с.

3. Каменская О.Л. Гендергетика - наука будущего // Гендер как интрига познания: гендерные исследования в лингвистике, литературоведении и теории коммуникации: Альманах. Пилотный выпуск. M., 2002. C. 13.

4. Dictionnaire de la langue française / Emile Littre. Tome 3. Paris, 1992. $1314 \mathrm{p}$.

5. Собственные материалы полевых исследований (ПМА, 2014 2016 гг.).

\section{References}

1. Alpatov V.M. Istorija lingvisticheskih uchenij. [History of Linguistic Teachings] M.: Jazyki russkoj kul'tury, 1998. 368 p.

2. Bogomolova O.I. Sovremenny frantsuzskiy yazyk: Teoretichesky kurs [Modern French: Theoretical Course]. M.: Izd-vo lit-ry na inostr-h jaz., 1948. 427 p.

3. Kamenskaya O.L. Gendergetika - nauka budushchego [Gender science the science of the future]. Gender kak intriga poznanija: gendernye issledovanija $v$ lingvistike, literaturovedenii i teorii kommunikacii [Gender as an intrigue of cognition: gender studies in linguistics, literature and communication theory]: Al'manah. Pilotnyj vypusk. M., 2002: 13.

4. Dictionnaire de la langue française / Emile Littre. V. 3. Paris, 1992. 1314 p.

5. Sobstvennye materialy polevyh issledovanij [Own field research materials] (PMA, 2014-2016). 


\section{ДАННЫЕ ОБ АВТОРЕ}

Черкесова Зарета Валериевна, кандидат филологических наук

Институт гуманитарных исследований - филиал Федерального государственного бюджетного научного учреждения «Федеральный научный иентр «Кабардино-Балкарский научный иентр Российской академии наук»

ул. Пушкина, 18, г. Нальчик, КБР, 365000, Российская Федеращчия

zara7belle@mail.ru

\section{DATA ABOUT THE AUTHOR}

Cherkesova Zareta Valerievna, Candidate of Philology

Institute of Humanitarian Studies (branch) Kabardino-Balkarian Science Centre of Russian Academy of Sciences 18, Pushkin Str., Nalchik, 365000, Russian Federation zara7belle@mail.ru 